Working Paper 8504

FIXPRICE MODELS FOR DYNAMIC STUDIES

By Eric A. Kades

The author wishes to thank Professors Truman

Bewley, James Tobin, and John Geanakoplos of Yale

University for a wide range of insights,

inspirations, and corrections.

Working Papers of the Federal Reserve Bank of Cleveland are preliminary materials, circulated to stimulate discussion and critical comment. The views expressed are those of the author and not necessarily those of the Federal Reserve Bank of Cleveland or the Board of Governors of the Federal Reserve System.

August 1985

Federal Reserve Bank of Cleveland 


\section{FIXPRICE MODELS FOR DYNAMIC STUDIES}

\section{Abstract}

This paper constructs fixprice (or disequilibrium) models of a simple general equilibrium macroeconomic model. Although within the general framework of Malinvaud (1977), we start with simpler models to explain the basic idea of disequilibrium. Later models are more fully developed so that firms as well as households can hold stocks. These static models are developed explicitly for dynamic extension in a companion piece Working Paper $\underline{8505}$.

\section{Introduction}

This paper presents some versions of the "fixprice" models described by Benassy, Dreze, and Malinvaud. Instead of imitating their focus on comparative statics results, we construct static models explicitly for dynamic studies (in Working Paper 8505). We interpret these simple general equilibrium models as aggregative macroeconomic models, and our objective (like much of the fixprice literature) is to show how such parametric price constraints explain the stylized facts of a disequilibrium world. 
To take the most popular example, disequilibrium theorists maintain that involuntary unemployment exists in the sense that, at given wages for standard labor services, workers often cannot sell all the labor services that they desire. We construct static models that admit these "facts." The companion to this paper shows that Keynesian outcomes are protracted in dynamic extensions of this model.

Many economists find it impossible to accept the short-run parametrization of prices in this model. They claim that price movements are the essence of the theory of value and thus of economics in general. These same economists have no qualms about working in Arrow-Debreu worlds where prices never move at a11. We agree with Drazen (1980) that the fixprice assumptions we use do no less damage to reality than the preposterous auctioneer. And al though empirical studies are not conclusive, they can support the use of fixprice models at least as comfortably as they can support flexprice assumptions (see, for example, Eckstein and Fromm [1968], Godley and Nordhaus [1972], and Okun [1975]). Some of these authors even present models in which price rigidities are a result of rational behavior. We do not pursue this line of inquiry, however; we merely note that economists cannot easily dismiss fixprice economies (even if only short-run) and resulting disequilibrium.

Beyond a subjective preference for equilibrium models as worlds where simple conservative policies work magically, the elegance of equilibrium models explains much of their appeal. In contrast, as we will see in this paper, disequilibrium models are extremely messy. But this is not sufficient reason to completely ignore a class of models that may remedy the key shortcoming of equilibrium models. Tobin (1980) has compared using equilibrium models because of their tractability to looking for a lost purse 
at night under a streetlight because the lighted area is the only part visible. If equilibrium theorists were not so bold in making policy recommendations from these models, no one would mind their searching. But they must remember that the purse might not be under their Walrasian lamp.

Certainly disequilibrium models are much less elegant than equilibrium models, but this is because they follow a more general approach. If any disequilibrium model can be solved, its equilibrium analog is trivially tractable. Thus, the only justification for avoiding disequilibrium models is complete confidence that all economies are always in equilibrium. We find this assumption stronger than all the assumptions made in this paper. Arrow-Debreu equilibrium cannot be said to hold tautologically in the real world, yet this is the implicit (and sometimes explicit) hypothesis of some authors. The special case of equilibrium must be justified before it can be convincingly used.

\section{Road Map}

Clower (1965) clearly inspired modern fixprice modeling. He emphasized that Keynesian explanations of involuntary unemployment could not be reconciled with Walrasian equilibria where no quantity constraints ever ration transactions. Equilibrium prices by definition balance trades under desired behavior. The implicit hypothesis is that prices clear markets-adjust infinitely faster than quantities. Clower says that Keynesian theories, by contrast, should postulate that quantities adjust infinitely faster than prices. He believes that only under such assumptions could general equilibrium models yield Keynesian outcomes. Leijonhufvud (1968) 
argued in much greater detail (though not precisely) how a fixprice model might produce involuntary unemployment. Hicks (1974) clearly emphasized that the major distinguishing feature of Keynesian models was a fixprice method in contrast to the classical flexprice approach. (Hicks coined the terms "fixprice" and "flexprice".) The rest of the literature examined in this paper can be seen as the formalization of these ideas in static models and their dynamic extensions.

The basic atemporal model consists of one aggregate household, one aggregate firm, and a government sector. The firm sells the good to the household and buys labor services from the household. Firms maximize profits; households maximize utility. The government finances its purchases by taxing all profits of the firms and finances deficits, if necessary, by printing money (or by destroying money if there is a surplus).

Since prices will not adjust to clear markets, we must have other forces to balance transactions. Our relatively weak conditions can be described as voluntary trade in efficient markets; we will state these conditions precisely below. These conditions alone do not completely determine fixprice allocations; a rationing scheme with some desirable properties must also be assumed. Manipulability is the most difficult issue in designing an acceptable rationing system. It is difficult to design a rationing system based on agents' preferences that does not encourage them to submit unstable bids in order to manipulate the rationing scheme and to procure more goods. Most disequilibrium theorists believe stochastic rationing best describes the real world (for the clearest discussion of this issue, see Honkapohja and Ito [1979]). But since we want to avoid the complications of describing the basics of a disequilibrium economy, we ignore the manipulability problem and its stochastic solution. 
Dreze (1975) first demonstrated the existence of equilibria in a fixprice economy. Benassy (1976) later proved existence of a similar theorem with a more Keynesian flavor. Silvestre (1982, 1983) has carefully demonstrated that these two types of fixprice equilibria are usually equivalent. For reasons discussed below, we find Benassy's definition more useful. We reproduce no existence proofs in this paper, however.

Fixprice equilibria are called "non-Walrasian." They are classified in aggregated macroeconomic models like ours according to which sectors are rationed in which markets. The essential point is that under alternative constraints, the behavior of each sector will differ. Although in the static model these differences are the entire point and are completely obvious, changing constraint sets (and thus, changing equilibria types) causes major complications when we deal with dynamics in our subsequent paper. Thus, we carefully examine the constraint sets and conditions for their existence in this paper. We note that at any given trading date (temporary equilibria), the exogenously determined price vector may clear markets with no rationing. This defines a walrasian equilibrium, which is thus seen as a special case of non-Walrasian equilibria.

The introduction of stock variables (money for the household and inventories of the good for the firm) looks formally superfluous in the static model, and so it is. But in a one-period model, stocks cannot be valued. We can justify their existence only implicitly. While we are lormally modeling only one temporary equilibrium, we imagine that the household and firm are preparing for a long future and thus value stocks of durable assets. We include these stock variables in the static model to simplify the process of filling out the dynamic model, where the stock variables play a key role in defining equilibrium paths. 
Because of the focus of this paper and its successor, we won't discuss the comparative statics of our model. Although, as with most economic models, the comparative statics of fixprice models have been investigated much more thoroughly than dynamics, we agree with Fisher (1984) that the stability (and ultimately even the speed of adjustment) of an equilibrium must be established before comparative statics results can be used convincingly. That is the role of Working Paper 8505 .

\section{The Simple (Stockless) Model}

In outlining the atemporal model, we illustrate the importance of the basic quantity-constrained idea by first presenting a model without any stock variables. Although other authors start with stock models, we believe this simple model best explains disequilibrium:

Notation

$L$ : units of labor transacted,

$Y$ : units of good transacted,

$W$ : nominal wage,

$\mathrm{p}$ : nominal price of good,

$w:$ real wage; $w=w / p$,

$x$ : exogenous parameter vector; in this model $x=(p, W)$.

Note that money exists only figuratively, as a unit of account to measure $w$ and $p$; there is no physical stock of money in the model yet. Consumers are completely described only by their endowments, consumption sets

(feasibility), and utility functions (choice criterion):

(1) $e$ : endowment vector of households,

$C=\left[(L, Y) \varepsilon R^{2}: L \leq L_{\text {max }}\right]$ : consumption set,

$\mathrm{U}: \mathrm{C} \quad \mathrm{R}_{+}$. 
$L_{\text {max }}$ is implicit beyond this point.

We assume that this utility function has all the usual properties:

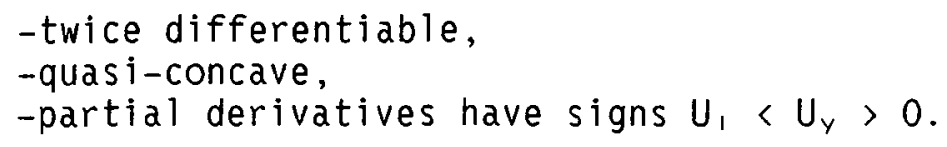

A simple production function, $F(L)$, describes the activity of the firm. It satisfies:

$$
\begin{aligned}
& - \text { twice differentiability } \\
& -F^{\prime}>0, \\
& -F^{\prime \prime}<0 .
\end{aligned}
$$

The profit function is:

$$
r(x)=\operatorname{pY}(x)-W L(x) .
$$

Note that actual transactions $(Y, L)$ depend only on the parameters. It is important to keep in mind that agents' demands will, in general, have additional (quantity) constraints.

We can now state the programming problem for each sector. The household maximizes utility over its constrained consumption sets; the firm maximizes profit subject to its production possibilities.

$$
\begin{array}{lllll}
\text { Household } & : \text { MAX } & U(L, Y) & \text { subject to } & L W \leq p Y . \\
\text { Firm } & : M A X & r(L, Y) & \text { subject to } & Y \geq F(L) .
\end{array}
$$

Although our assumptions do not positively insure the existence of an equilibrium price vector $(p, w)$, this economy essentially fits the Arrow-Debreu framework (Debreu 1959) and so we assume there exist Walrasian equilibria to this economy. But to simplify matters, especially in the dynamic analysis in Working Paper 8505, we also desire the uniqueness of (Walrasian) equilibrium in our model. There are still no necessary conditions for uniqueness extant (however, see Grandmont, Kirman, and Neuefeind [1974]). We make a strong sufficient assumption for uniqueness of Walrasian equilibrium: gross substitutability of each good for all other goods (Arrow and Hahn, [1971]). In the general n-good, m-agent, 
Arrow-Debreu mode1, the gross substitutes assumption is extremely

restrictive, but in our two-good, two-agent world it requires only mildly stronger assumptions than we have already made. This assumption will become stronger when we add the stock variables money and inventories to the economy. Note that gross substitutability is a very classical assumption to make. It allows the traditional price mechanism to work smoothly, yet it does not prevent our economy from reaching Keynesian outcomes.

Our unique Walrasian equilibrium could easily be computed under gross substitutability by a contraction mapping in excess demands. We could economically interpret this as the classical tatonnement process. Thus, although they are hypothetically parametric to the agents in terms of their final demands, prices are really variables in equilibrium models to be determined by the characteristics of the agents.

We call the Walrasian quantity decisions of the agents (at a given, usually disequilibrium, parameter vector) notional quantities (Clower [1965]). These are marked with an asterisk superscript. Households are referenced by an " $h$ " superscript; firms are denoted by an "f". So, for example, we denote notional labor supply by $L^{h *}$ or good demand by $Y^{n *}$. Although in Walrasian economies such a script is superfluous since the two quantities are by definition equal in equilibrium. It is the essence of the fixprice/disequilibrium approach that these quantities are not equal--that markets do not clear under notional desires.

The source of an equilibrium price vector is a tatonnement where prices adjust to walrasian values before any trade or production is allowed to take place, so that notional demands and supplies are equated. Most theorists don't even attempt to defend the tatonnement as a plausible method for price 
adjustment and attainment of equilibrium over time. The process doesn't stem from the maximizing behavior of any agents; no matter how it is rationalized, it requires strong efforts to instantaneously gather and process all the information in the economy.

The fixprice method opts for the other extreme. Instead of assuming that the very special Walrasian price vector is found, this approach imagines that the price vector is truly parametric at a given trading date and will be Walrasian only by accident. The literature has then explored how an economy with such a price vector will work.

There is no reason to believe that notional supplies and demands will clear markets at an arbitrary price vector; this only occurs in economies where almost every price vector is a Walrasian equilibrium. Debreu (1970) has shown that for a broad class of economies (easily including a more fully specified version of ours) almost no price vectors attain equilibrium--in the Euclidean price space the number of Walrasian price vectors is generically finite.

More structure must be imposed to determine actual transactions. This is the problem with fixprice equilibria. The most basic requirement imposed in fixprice models is voluntary trade: no agent is ever forced to trade (supply or demand) more of a good than he desires--what his preferences dictate. Since markets do not clear, and we disallow forced transactions, agents will have to be rationed in quantities at the given price vector to make trades balance.

We briefly discuss the two most popular proofs of the existence of equilibria with rationing. Dreze (1975) has agents perceive fixed quantity constraints in each market: $L, Y$. In our simple model, Dreze demands are 
derived from the new quantity-constrained maximization problems:

Households: $\operatorname{MAX} U(L, Y) \quad$ subject to $\quad p Y \leq W L ; \quad L \leq \bar{L} ; \quad Y \leq \bar{Y}$ Firms: $\quad \operatorname{MAX} r(L, Y)$ subject to $Y \leq F(L) ; L \leq \bar{L} ; \quad Y \leq \bar{Y}$.

Dreze proved that under general conditions this economy will have a fixprice equilibrium. Equilibrium here means the maximization of quantity-constrained utility and profit functions with trades balancing. We denote these quantity-constrained Dreze demands with double bars above the variables:

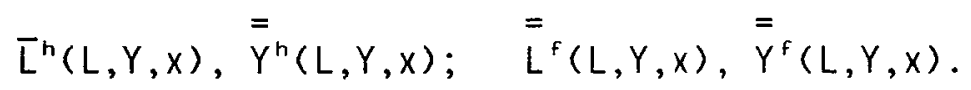

With this same notation, we can define the second type of fixprice equilibria: Benassy equilibria. Benassy demands, which we will refer to (following the ideas of Clower, [1965]) as effective demands, are derived from considering all constraints, except the constraint in the individual market where demand is being formed. We denote them with a + superscript; they are defined from the maximization problems:

(8) Households: $L^{h+}=\operatorname{MAX} U(L, \bar{Y}, x)$ subject to $W L \leq p Y$

$$
Y^{n+}=\operatorname{MAX} U(\overleftarrow{L}, Y, X) \quad \text { subject to } W L \leq p Y
$$

Firms: $\quad L^{f+}=\operatorname{MAX} r(L, \bar{Y}, X)$ subject to $Y \leq F(L)$

$$
Y^{f+}=\operatorname{MAX} r(\bar{L}, Y, X) \quad \text { subject to } Y \leq F(L)
$$

These are related to Dreze demands by:

$$
\begin{aligned}
& L^{h+}=\bar{L}^{h}(\infty, Y, x), \\
& Y^{h+}=Y^{h}(L, \infty, x), \\
& L^{f+}=\overline{\bar{L}}^{f}(\infty, Y, x) \\
& Y^{f+}=\overline{\bar{Y}}(L, \infty, x) .
\end{aligned}
$$


There is no guarantee that effective demands will be less than or equal to the actual constraints; agents' transactions will be governed by the smaller of the two effective demands in a given market. So the exogenous constraints in Dreze demands turn out to be the minimum of the effective demands when the system of simultaneous Benassy demands is solved. Benassy demands endogenously determine the perceived constraint levels and are thus preferred to Dreze demands.

We develop some graphical tools to represent this model. They are useful for illustrating our simple general equilibrium and will be essential to the analysis of more complicated models. We will be graphing the behavior of the household and firm in the trade space $(L, Y)$. The firm simply obeys "efficient production" in this model and always produces somewhere along the production function $Y=F(L)$. However the firm will never produce more than its Walrasian point $\left(L^{f *}, Y^{f *}\right)$ under the given wage and price (the exogenous parameter $x$ ), since beyond this point the exogenous wage exceeds labor's marginal product.

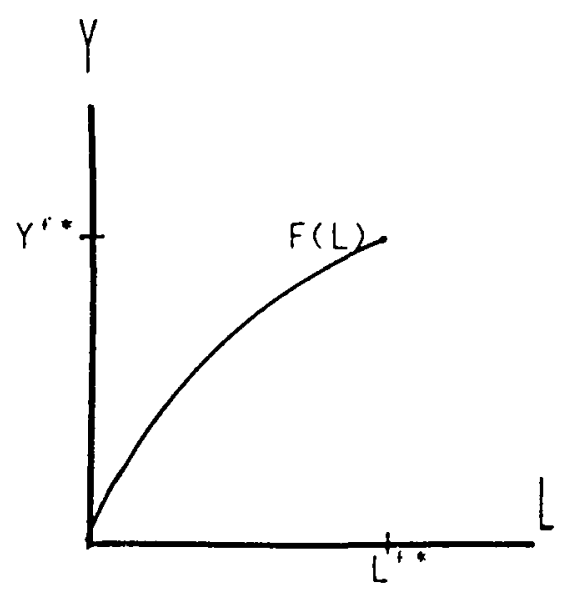

Figure 1: Firm's demand (production function)

The shape stems from our assumptions on the production function.

The household obeys "efficient consumption"; it consumes along a line going through the origin (no work, no pay) the slope of which is dictated by 


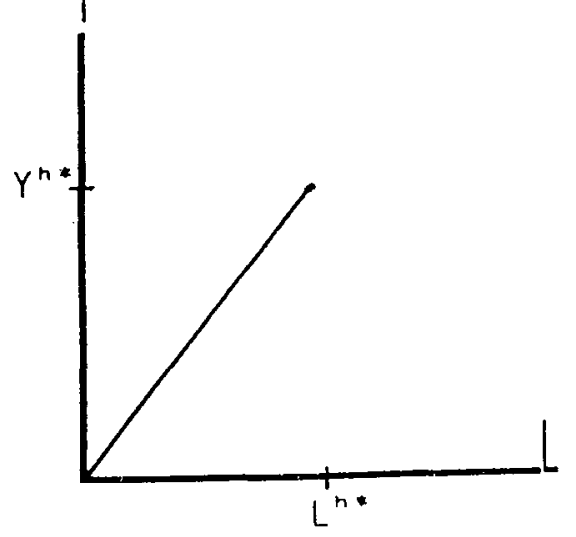

Fiqure 2: Household demand (consumption expansion line)

The household will never work beyond its notional quantities ( $\left.L^{n *}, Y^{h *}\right)$, since beyond this point, the marginal utility of the good falls below the marginal utility of leisure.

To determine the fixprice equilibrium, we combine the two curves:

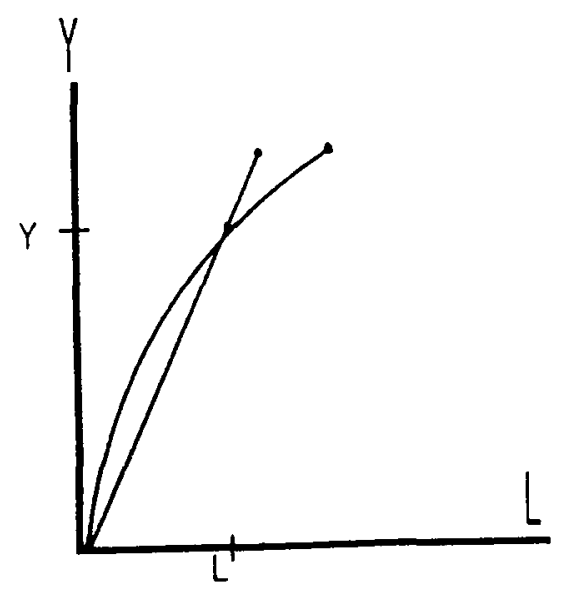

Figure 3: General equilibrium for stockless model

extensions. We could introduce price dynamics by comparing notional and effective demands at a given date and by allowing prices to change between trading dates according to the law of supply and demand. But we will argue that a better measure of communicated excess demand is a comparison of effective demand with actual transactions. In this narrow model, effective demands equal transacted quantities for both sectors, and so these price dynamics do not apply. 


\section{The Full Model}

We now enrich the model by adding a stock variable for each sector:

money for the household and inventories for the firm. We also introduce the government, which is central to the accounting framework we set up to balance stock holdings. The model begins to be intertemporal here, though not dynamic.

Notation

$\bar{M}=$ end period money holdings of households in a given period, $M=$ initial money holdings of households in a given period,

$\vec{m}=$ real money holdings; $m=M / p$,

$\bar{i}=$ end period inventory holdings of firms in a given period,

$i=$ initial inventory holdings of firms in a given period,

$\bar{g}=$ government purchases of the good in a given period,

Intertemporal adjustments are dictated by the following equations:

$$
\begin{aligned}
(10) \bar{M} & =\underline{M}+W L-p Y, \\
\bar{i} & =\underline{i}+F(L)-Y .
\end{aligned}
$$

To our previous assumptions on the utility function we now add:

$$
\partial U / \partial \mathrm{m}>0 \text {. }
$$

Thus we are committing the offense of placing money in the utility function. Its utility derives from an implicit promise of future consumption of the good beyond the time horizon of this model.

Government expenditures are financed in two ways. First, all profits of the firms are taxed so that we needn't worry about the firm holding money. Any resulting deficit or surplus is financed by the creation or destruction 
of money in trade for the good. This deficit must be accepted by the household as money savings. Analytically this says:

$$
\Delta M=p g-r=W L-p Y .
$$

Government demand is never rationed.

To make firms desire inventories, we add a "valuation of stocks" function (van den Heuvel 1984) to their objective function. We label this function $v(i)$ or equivalently $v(x)$; $v$ maps $R_{+}$into $R_{+}$. We assume:

$$
\begin{aligned}
& -v^{\prime}>0 \\
& -v^{\prime \prime}<0 \\
& -v \text { is twice differentiable. }
\end{aligned}
$$

We then define the firm's new objective function as the sum of profits and valuation of inventories:

$$
R(x)=r(x)+v(x) \text {. }
$$

Our maximization problems are almost the same, but now the stock variables $M$ and $\underline{i}$ enter the constraints as exogenous parameters, and $M$ and $i$ enter the objective functions:

$$
\begin{array}{lll}
\text { Households: } & \operatorname{MAX} U(L, Y, M) \text { s.t. } \bar{M}=\underline{M}+W 1-p Y \geq 0 . \\
\text { Firms: } & \operatorname{MAX} R(L, Y, \dot{j}) \text { s.t. } \bar{i}=\underline{i}+F(1)-y \geq 0 .
\end{array}
$$

For given values of the exogenous real parameter vector $x=(w, m, i)$, we will have our fixprice equilibria, since our economy still admits the Benassy existence proof. Also, we still asssume gross substitutability so that the notional equilibrium of the economy, considered as an Arrow-Debreu model with a tatonnement, still yields a unique equilibrium price vector. 
Note that we can use our stock adjustment identities to supress the appearance of $m$ and $i$ in these maximization problems so that the maximands read:

$$
\begin{aligned}
& U(L, Y, \underline{M}+W L-p Y), \\
& R(L, Y, \underline{j}+F(L)-Y)
\end{aligned}
$$

and the inequality constraints can also be stated without end of period stocks.

Effective demands are defined exactly as they were in the stockless mode1. Dreze demands stem from the maximization problems:

(17) Households: $\operatorname{MAX} U(L, Y, X)$ s.t. $M+W L-p Y \geq 0 ; \leq L \leq L ; Y \leq \bar{Y}$, Firms: $\quad \operatorname{MAX} R(L, Y, X)$ s.t. $\underline{i}+F(L)-Y \geq 0 ; L \leq \bar{L} ; Y \leq \bar{Y}$,

where $x=(w, m, i)$.

These solutions are labeled:

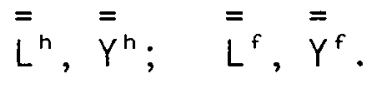

Then the Benassy or effective demands can be defined by:

$$
\begin{array}{ll}
\text { Households: } L^{h+}=\operatorname{MAX} U(L, \bar{Y}, X) \quad \text { subject to } \underline{m}+w L-Y \leq 0, \\
Y^{h+}=\operatorname{MAX} U(L, \bar{Y}, X) \quad \text { subject to } \underline{m}+w L-Y \leq 0, \\
\text { Firms: } & L^{f+}=\operatorname{MAX} R(\underline{L}, \bar{Y}, X) \quad \text { subject to } \underline{i}+F(L)-Y \leq 0, \\
& Y^{f+}=\operatorname{MAX} R(\bar{L}, Y, X) \quad \text { subject to } \underline{j}+F(L)-Y \leq 0 .
\end{array}
$$

These are related to Dreze demands by:

$$
\begin{aligned}
& L^{n+}=\bar{L}^{n}(\infty, \bar{Y}, x), \\
&=\overline{Y^{n+}}= \\
& Y^{n}(\bar{L}, \infty, x), \\
& L^{f+}=\bar{L}^{f}(\infty, \bar{Y}, x), \\
& Y^{f+}=Y^{f}(\bar{L}, \infty, x) .
\end{aligned}
$$

All we have done to the basic fixprice model is add two more exogenous parameters to the vector $x$. 
Like many general equilibrium models, analytic techniques are not very tractable or enlightening here. So we will continue to develop the graphic tool introduced above to capture the essential features of our increasingly complex models.

We begin in the $[L, Y, U(L, Y)]$ version of $R^{3}$ and examine the behavior of the household. More good and less work are always preferred, and before constraints are imposed, there is no bounded solution to utility maximization in the trade space $(Y, L)$. However, this space omits stock variables, and we know that money is valued in the household's objective function. Both prices and initial stocks are implicit in final stock holdings, so they may be represented implicitly in this diagram. Since our system, when considered as a Wairasian economy, has a unique equilibrium, the constrained utility manifold looks like the following:

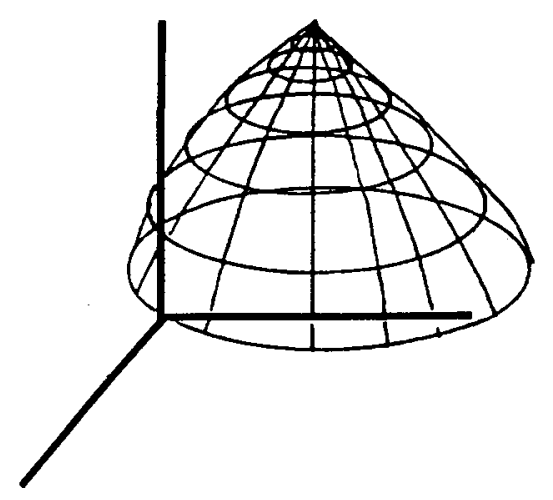

Figure 4 Constrained utility manifold; money implicit

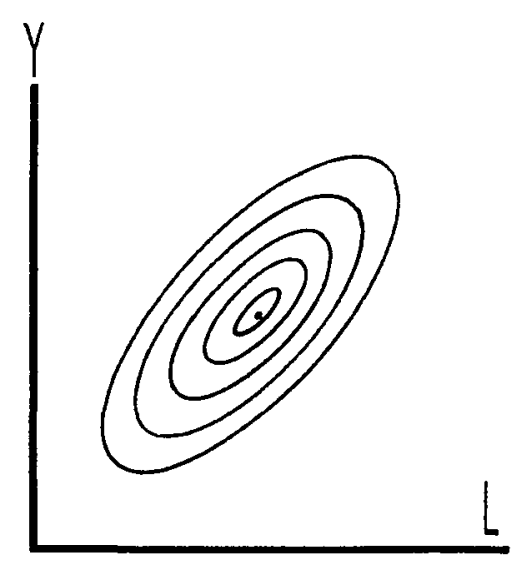


The value of $U$ is maximized at the Walrasian equilibrium and level curves further from the WE point represent lower levels of utility. The price constraints are implicit here with the definition of end-of-period money holdings.

Deriving the effective demand curves is natural with this graphic device. To find the effective demand curve of the household for the good (to take a definite example), we consider every possible level of constraint in the other market (labor) and assuming that level of constraint ( $L)$ prevails, we ask what the demand for the good will be. This is solved by maximizing utility (selecting the level curve of $U$ closest to WE) subject to $L=L$ (all other constraints are implicit in the transformed utility function). Graphically this is represented by finding the point of tangency of the $L=L$ line with a level curve of the stock-implicit, constrained utility function. By doing this for all levels of $L$ between 0 and $L^{n *}$, we have the effective demand locus of households for the good, $Y^{h+}(L, X)$ :

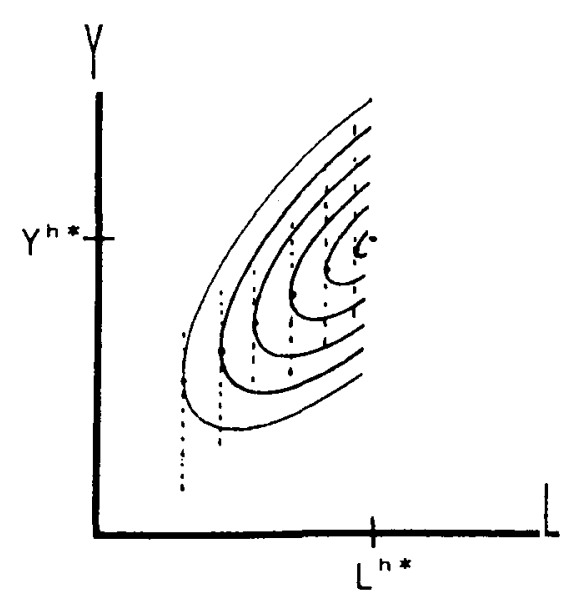

Figure 6 Graphical derivation of effective demand for the good 


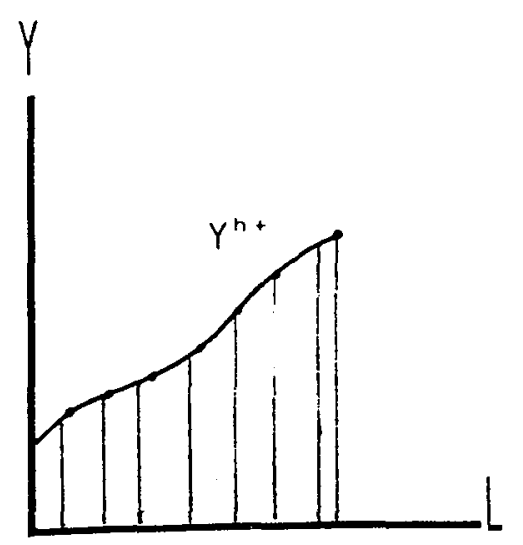

Figure $7 Y^{n+}$; effective demand for the good by the household

To indicate our voluntary trade assumption, we shade the area below the effective goods demand curve: the household will never voluntarily trade above the curve, although rationing may force it to trade below this locus. The positive intercept indicates that even if it does not labor, the household will consume out of its money stock.

A parallel procedure, reversing the roles of $Y$ and $L$, yields the effective supply of labor by households, $L^{n+}$ :

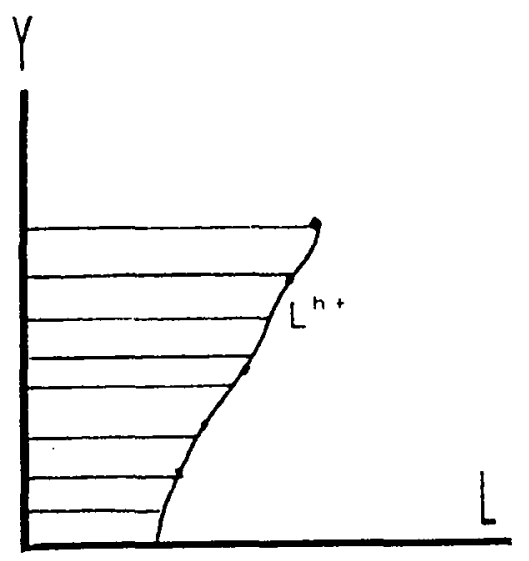

Figure 8 Effective supply curve of labor 
The shaded area to the left of the curve indicates the voluntary trade rule for labor supply. The positive intercept indicates that work is performed even in the hypothetical case of no consumption, since the accumulation of money stocks is desired enough to offset the disutility of some level of labor.

Combining these two diagrams we have the voluntary trade set of the household:

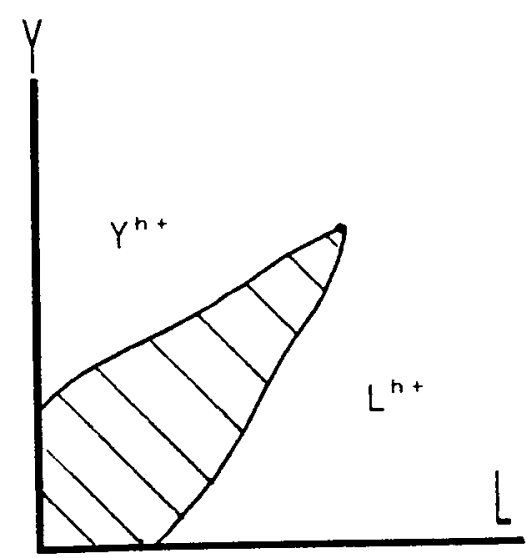

Figure 9 Voluntary trade set for households

The shape of these curves doesn't necessarily follow from our assumptions; they do have to intersect the axes as represented, but their slopes could be negative over some regions of the space or even over all of it. However, if we add the assumption that:

$$
\partial^{2} U / \partial L \partial Y>0 \text {, }
$$

we can show that both curves have positive slopes. We have for the effective labor supply curve:

$$
L^{h+}=\operatorname{MAX} U(L, Y, X) \quad \text { s.t. } \underline{m}+W L \leq Y .
$$

Then the first order maximization condition gives:

$$
\partial U / \partial L=\partial U\left[L^{h+}(Y, X)\right] / \partial L=0 .
$$


The concavity of $U$ implies:

$$
\partial^{2} U / \partial L \partial L<0 .
$$

Then applying the implicit function theorem to the first order conditions to solve for $\partial L^{h+} / \partial Y$ we have:

$$
\frac{\partial L^{h+}}{\partial Y}=\frac{\partial^{2} U\left[L^{h+}(Y, X), Y, X\right] / \partial L \partial Y}{\partial^{2} U\left[L^{h+}(Y, X), Y, X\right] / \partial L \partial L}
$$

Then it is easily seen that our assumption (21) is a necessary and sufficient condition for a monotone increasing $L^{h+}$ locus in $(L, Y)$ space.

A parallel derivation for the effective demand curve for the good yields

$$
{\frac{\partial Y^{n+}}{\partial L}}^{n}=\frac{\partial^{2} U\left[L, Y^{h+}(L, X), X\right] / \partial L \partial Y}{\partial^{2} U\left[L, Y^{n+}(L, X), X\right] \partial Y \partial Y}
$$

and under concavity of $U$ and our assumption on $\partial^{2} U / \partial L \partial Y$, we have positivity of this derivative.

We will need some assumptions on the signs of the derivatives of the notional and effective demands of the household, with respect to the parameters for our dynamic studies. We have included brief economic rationales for these assumptions:

$$
\begin{array}{ll}
\partial L^{n *} / \partial m, \partial L^{n+} / \partial m<0 & \text { (wealth substitues for labor } \\
\partial L^{n *} / \partial w, \partial L^{n+} / \partial w>0 & \begin{array}{l}
\text { (substitution effect dominates } \\
\text { effect in labor supply income), }
\end{array} \\
\partial Y^{n *} / \partial m, \partial Y^{+} / \partial m>0 & \text { (wealth encourages consumption), } \\
\partial Y^{n *} / \partial w, \partial Y^{n+} / \partial w>0 & \begin{array}{l}
\text { (higher wages encourage } \\
\text { consumption). }
\end{array}
\end{array}
$$

The effective demands of the firm are analagous to those of the household. We can start in $(L, Y, R)$ space and illustrate the unique maximizing value for the profit plus inventory evaluation function of the firm under the stock-constrained objective function. Using the level curves of the objective function in $(L, Y)$ space we could then find points of tangencies with constraint levels between zero and the Walrasian levels to give the effective demand curves for the firm: 


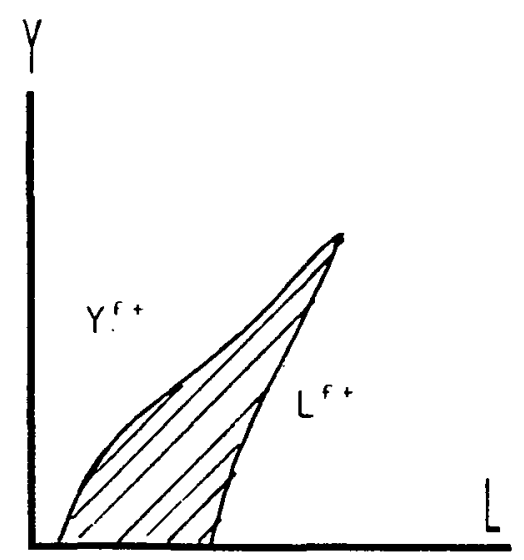

Figure 10 Effective demands and voluntary trade set of the firm

The intercept for the firm's effective goods supply $\left(Y^{f+}\right)$ lies on the $L$ axis, since even with no current goods transactions the firm desires to se11, while the effective demand curve for labor $\left(L^{f+}\right)$ intercept illustrates that the firm hires labor to accumulate inventories in spite of the lack of current sales. The monotone positive slopes of these curves follow with no further assumptions; the production function provides enough structure to yield these results. The effective demand for labor is given by:

$$
L^{f+}=\operatorname{MAX} R[L(Y, X), Y, X] \quad \text { s.t. } F(L)+\mathfrak{i} \leq Y .
$$

The first order conditions for maximization give:

$$
\partial R[L(Y, X), Y, X] / \partial L=0 .
$$

We have $R(x)$ concave trivially as the linear combination of the concave function $v(x)$ and the linear function $r(x)$. The concavity of $R(x)$ implies: (30)

$$
\partial^{2} R / \partial L \partial L<0
$$


Then applying the implicit function theorem to the maximization conditions, we have:

$$
{\frac{\partial L^{f}}{\partial L}}^{+}=\frac{\partial^{2} R\left[L^{f+}(Y, X), Y, X\right] / \partial L \partial Y}{\partial^{2} R\left[L{ }^{f+}(Y, X), Y, X\right] / \partial L \partial L}
$$

So we need to show that:

$$
\partial^{2} R / \partial L \partial Y>0 \text {. }
$$

So we need to show that:

By defintion of the firm's objective function, we qualitatively have:

$$
\partial^{2} R / \partial L \partial Y=\left(V^{\prime \prime}\right)\left(F^{\prime \prime}\right)=(-)(-)=(+)>0 \text {. }
$$

Then the concavity of the valuation of inventory function gives our result. A similar proof estabishes that $Y^{f+}$ is monotonically increasing in $L$.

Finally, the signs of the partial derivatives of the notional and effective demands of the firm with respect to the parameters do not need to be assumed; they follow from the implicit function theorem:

$$
\begin{array}{ll}
\partial L^{f *} / \partial w=1 /\left(\partial^{2} f / \partial L \partial L\right)>0 ; & \partial L^{f+} / \partial w<0, \\
\partial L^{f *} / \partial i=0 ; & \partial L^{f+} / \partial i<0, \\
\partial Y^{f *} / \partial w=w /\left(\partial^{2} f / \partial L \partial L\right)<0 ; & \partial Y^{f+} / \partial w=0 . \\
\partial Y^{f *} / \partial i=1 ; & \partial Y^{f+} / \partial i=0 .
\end{array}
$$

We now examine the general equilibrium of the economy when both sectors carry stock variables in an intertemporal world. But, to pin down a solution, we must specify further conditions on markets; the voluntary trade 
sets of each sector will, in general, have a large intersection.

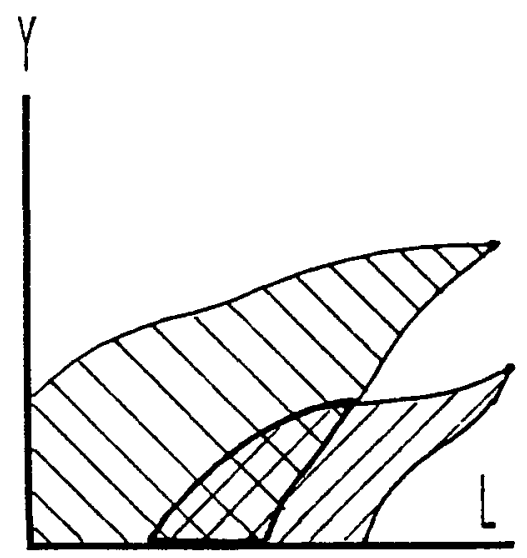

Figure 11 Size of voluntary trade set.

We assume that only one side of a market can be rationed--the agent with the smaller effective demand will always have this demand fulfilled. The usual terminology is to say that only the long side of a market is rationed. Efficiency of the markets (in some sense) is invoked to justify this assumption. This is not the classical idea of efficiency, in which markets, through flexible prices, always reach Pareto optimal outcomes, but a more limited notion that disallows the possibility of unsatisfied buyers and sellers in the same market. Graphically we see:

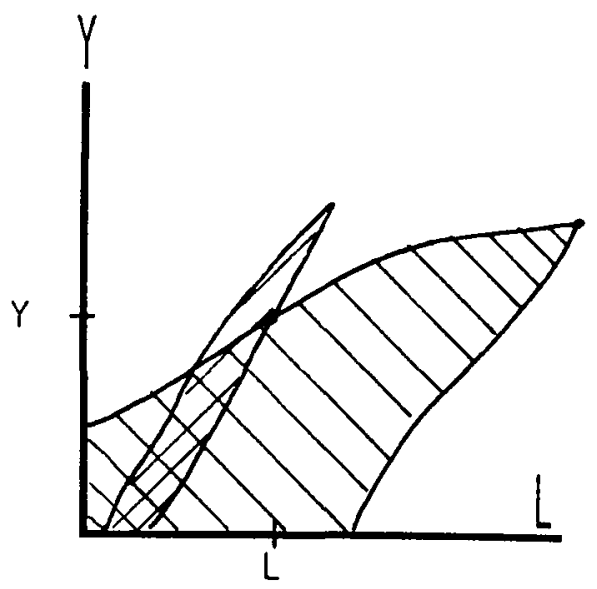

Figure 12 An example of general equilibrium in the model. 
By combining the demand curves, and thus the voluntary trade sets, of each sector we produce a community voluntary trade set (the cross-hatched area on the graph). Assuming that only the long side is rationed, amounts to saying that the northeastern-most point of the community voluntary trade set is achieved. Equivalently, transactions are determined by the intersection of two minimal effective demand curves. The salient distinction among various equilibria is which sectors are rationed in which markets. We classify five different equilibria types by the structure of constraints.

First, there is the possibility that we will actually have a Wairasian equilibrium, if the notional demands of the household and firm coincide under the given parameter vector $x=(w, m, i)$.

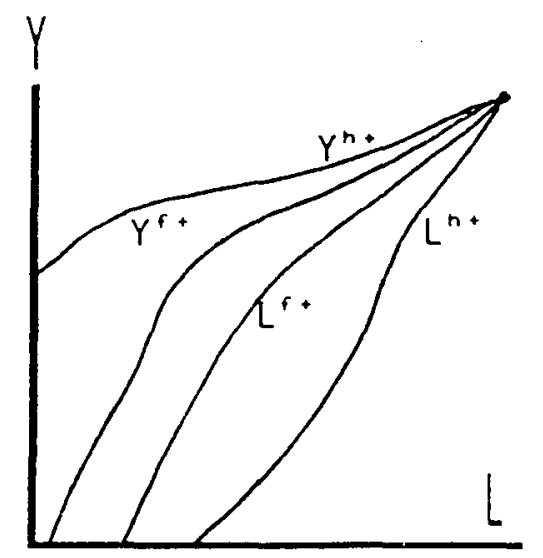

Figure 13 Walrasian Equilibrium (WE).

We label this equilibrium (WE). It can be thought of as allowing $p$ and $w$ (or w) to vary until our unique Walrasian outcome is found under the other given parameter values. We have already discussed existence and uniqueness of this outcome to our economy. Many authors, Dehez and Gabszewicz (1977) 
and van den Heuvel (1984), for example, have studied the stability of WE in this model extensively. We therefore wish to reiterate the accidental nature of such an outcome in fixprice economies. A temporary equilibrium process will almost never yield a WE. Our view is that only if all other types of equilibria are unstable, does it make any sense to examine the stability of the Walrasian outcome. If any other state is stable, then such an outcome will be generic relative to the WE.

Our next equilibrium type involves general excess supply. The household cannot sell all the labor it wishes, and the firm's effective goods supply desires are constrained.

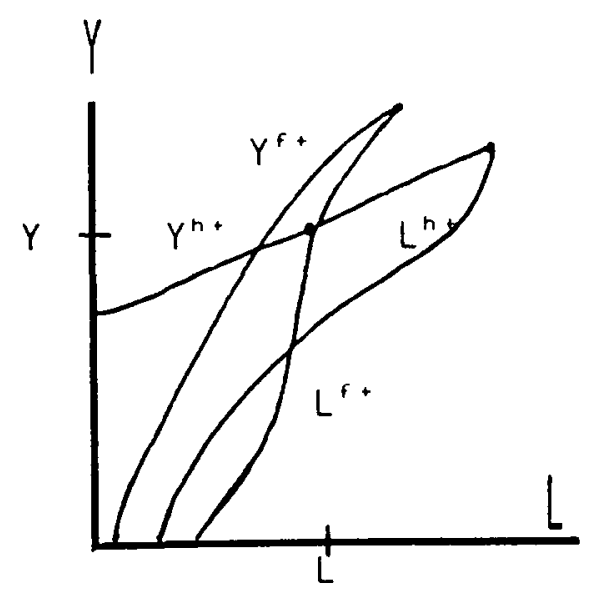

Figure 14 Keynesian Equilibria (KE).

We call this outcome a Keynesian equilibrium (KE). Note that figure 12 shows another configuration of effective demands that gives a $K E$.

In the other extreme, we may have excess demand for the good by households and excess demand for labor by the firm--general excess demand. 


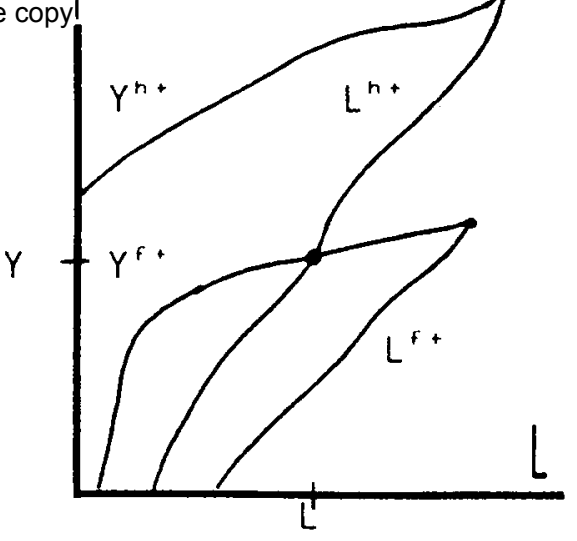

Figure 15 Inflationary Equilibria (IE).

This has been called an inflationary equilibrium (IE) in the literature. Since this terminology is deceptive in our static fixprice setting, we prefer to call it repressed inflation.

We will be most interested in KE and IE because it is not at all clear what direction real prices (the real wage) should change to alleviate the non-Walrasian structure of effective demands. The "law of supply and demand" fails to give a us an answer, and we may find stationary real price paths away from the WE. This is fundamental to disequilibrium dynamics.

The remaining two equilibria states have effective demands that enable the conventional price mechanism to work. In classical equilibria (CE), the household is constrained in both markets; there is an excess demand for the good and an excess supply of labor.

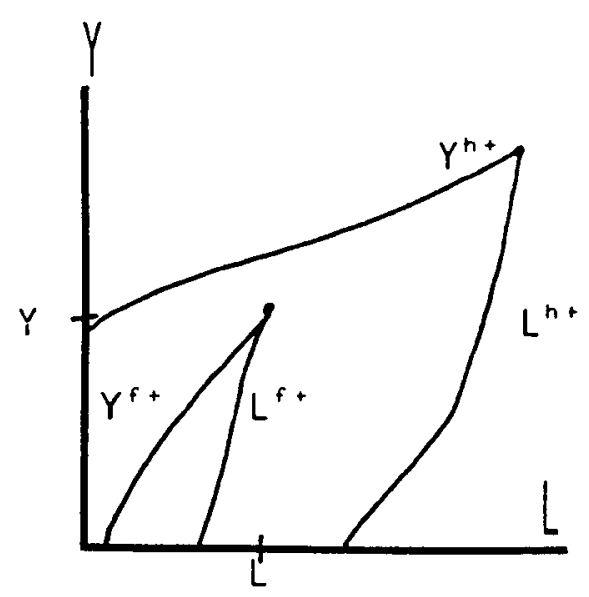

Figure 16 Classical Equilibirum (CE). 
The name stems from the fact that, in this equilibrium, a decline in the real wage moves the economy toward the WE and improves the welfare of both agents. Wage cuts were the remedy for unemployment recommended by classical economists in Keynes' time (Pigou, Robbins, Hayek, and Haberler, among others). In this situation, the accusation that the high level of wages is the cause of unemployment is justified.

Finally, if the firm is constrained in both markets, we have underconsumption equilibrium (UE).

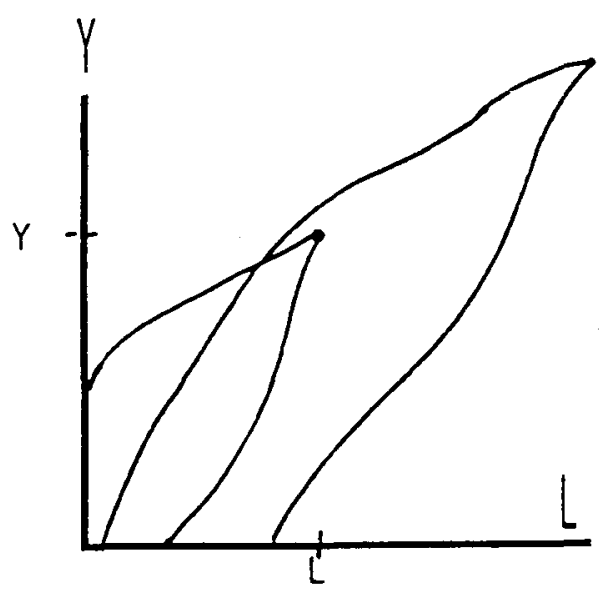

Figure 17 Underconsumption Equilibrium (UE).

In this case, a rise in the real wage allows the firm to sell more and thus hire more labor. Welfare improves for both agents.

We briefly note that for an exhaustive classification, we must distinguish four more types of equilibria because on the borders between KE, IE, CE, and UE there are different sets of quantity constraints. We present one example, the case between KE and CE. 


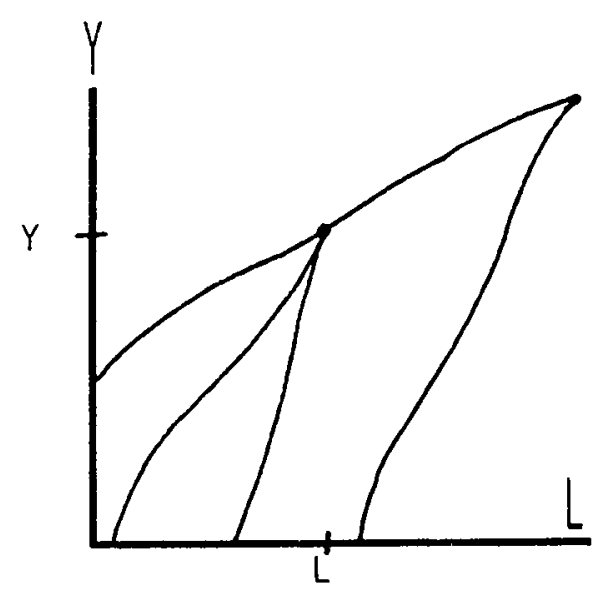

Figure 18 Equilibrium between $\mathrm{KE}$ and $\mathrm{CE}$ (KE/CE).

Here the household is rationed in labor sales, but neither sector faces active quantity constraints in the goods market. Analogous constraint combinations could occur between KE/UE, CE/UE, and CE/IE. Because KE/IE and CE/UE present opposite pairs of constraints, the border between these cases degenerates to the WE with no rationing. This will be clearer below when we map the equilibrium types in parameter space.

So far, we have graphically shown only one transaction under each set of effective demand functions. This does not necessarily follow from our assumptions; demands may be such that there is no point unambiguously furthest northeast. One possible example is shown in figure 19.

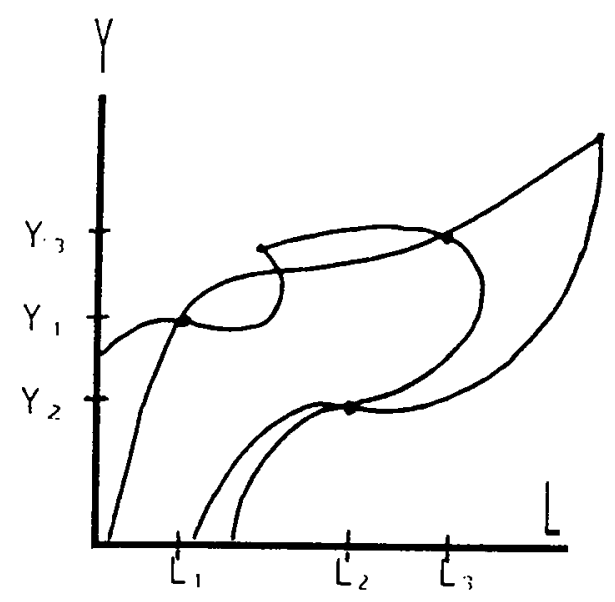

Figure 19 An example of multiple transactions. 
It is clear that this cannot arise if one set of curves is steeper than the other. Other authors make some supposedly weaker assumptions and prove what we will simply assume:

$$
\begin{aligned}
& \partial L^{f+} / \partial L>\partial L^{h+} / \partial L, \\
& \partial Y^{f+} / \partial L>\partial Y^{h+} / \partial L .
\end{aligned}
$$

When considered with the established positions of the intercepts of the effective demand curves, this equation yields a unique equilibrium in the mode1. These assumptions are based on the observation that household demands seem to vary less in the real world than do business decisions.

So far, we have operated in the trade space $(L, Y)$. In dynamic studies however, we are not so much interested in the movements of trades as in the convergence of the variables to steady states--dynamic equilibrium of money, inventory stocks, and prices. Thus we make use of graphs due to Malinvaud (1977) that define the range of parameter values for which each type of equilibria occurs (WE, KE, IE, CE, or UE). Under our assumptions, we know that each set of parameter values implies a unique equilibrium.

The vector of real parameters is $x=(w, m, i)$. Since $x$ still possesses too many dimensions to be presented pictorally, we show the positions of the equilibria in all three, two-member subsets of the parameter vector ([m,w], $[m, i],[i, w])$.

To find these regions, we examine which constraints are binding at the boundaries between two states and use the implicit function theorem to solve for the derivative of one of the state variables in terms of the other. The omitted parameter is kept constant. In most cases, the sign of the slope of the border is determinate under this procedure; we make clear graphically the few cases for which this is not true. Using the fact that all four such 
lines must meet at the Walrasian equilibrium, and knowing which states are adjacent (by comparing constraint structures), we are able to place the four regions in each parameter subspace.

To be fully explicit, we would have to solve for four such boundaries in three parameter subspaces, a repetitious exercise in the implicit function theorem and intricate calculus. Therefore we will fully derive the KE/CE boundary in $(m, w)$-space and then graphically present the rest of the results.

The KE/CE boundary is defined by

$$
\begin{aligned}
& Y=Y^{h+}=Y^{f *}, \\
& L=L^{f *} .
\end{aligned}
$$

This situation can be summarized by:

$$
Y^{h+}\left(L^{f *}, X\right)=F\left(L^{f *}\right)-\dot{i}
$$

Rewriting this expression with the parameters expressed as $[m, w(m)]$, we have:

$$
Y^{h+}\left[L^{f *}(w(m)), m, w(m)\right]-F\left[L^{f *}(w(m))\right]+i=0 .
$$

Then by applying the implicit function theorem, we can solve for $\mathrm{dw} / \mathrm{dm}$ :

$$
\frac{d w}{d m}=\frac{-\frac{\partial^{h+} / \partial m}{\partial Y^{h+} / \partial w+\partial L^{f *} /\left(\partial \bar{Y}^{h+} / \partial L-\partial F / \partial L\right)}}{}
$$


Under assumptions (3), (27), and (34) this expression is negative, so in $(m, w)$ space we have:

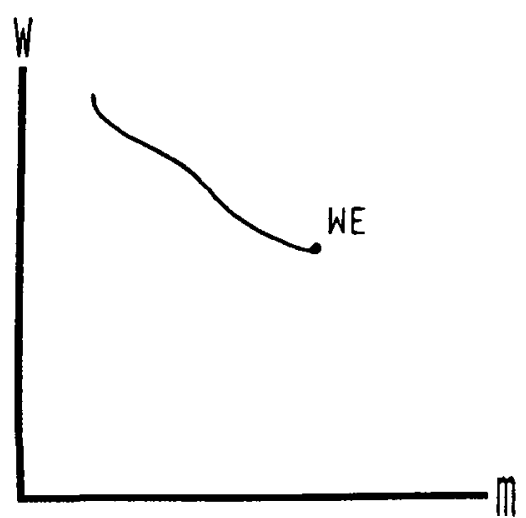

Figure 20 The KE/CE border in $(m, w)$ space.

It is easy to determine that the CE region lies above the KE/CE border by examining the effects of higher wages on the constraint structure.

After doing this for each boundary in each parameter subspace, we derive the following diagrams:

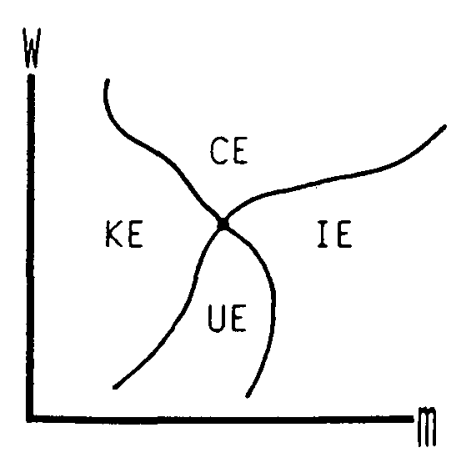

(a)

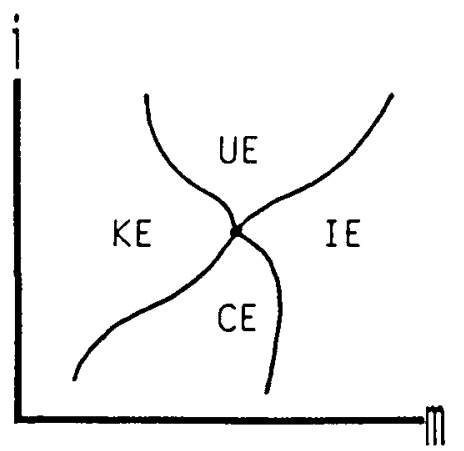

(b)

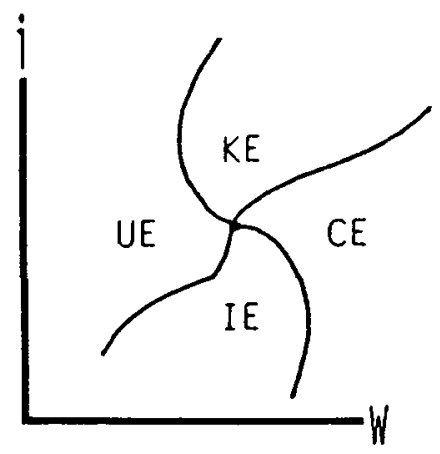

(c)

Figure 21 Divisions of parameter spaces by equilibrium type.

This completes our formal study of the general static model with implicitly valued intertemporal stocks. 
Although this model is more complete than earlier models (Malinvaud [1977], Bohm [1978], Honkapohja [1979]), which lacked a stock variable for the firm, the third state variable (inventories) greatly complicates dynamic analysis. Thus our preliminary dynamic investigations (in Working Paper 8505) will be conducted on simpler models lacking one of the stock variables. We will not present these models as fully as the general model above, but will graphically summarize the inventoryless economy to capture the essential differences when one stock variable is omitted.

Without inventories, the sole criterion in the firm's profit maximization problem is efficient production, as it was in the simplest model without any stock variables for either sector. The model's two effective demand curves $\left(L^{f+}, Y^{f+}\right)$ collapse into the production function in the trade space $(L, Y)$. Then it makes no sense to say that the firm is constrained in both markets, and UE disappears. We still have WE, KE, IE, AND CE (for brevity we omit the graph of WE; it is again the coincidence of the notional points of the effective demand curves).

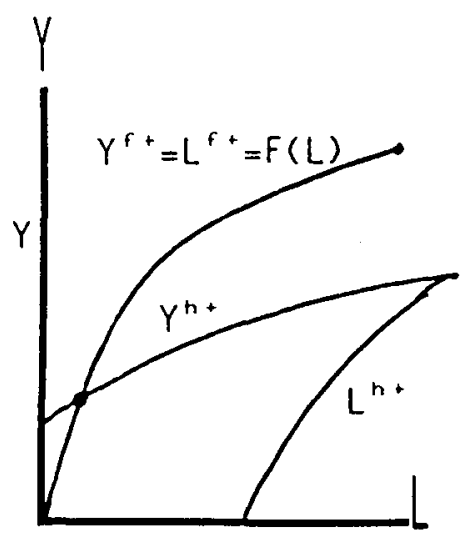

L (a)

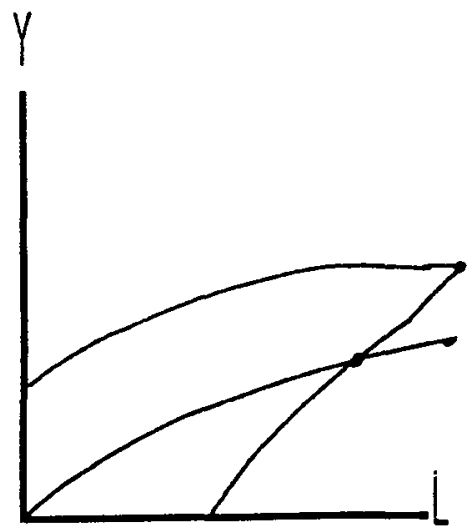

(b)

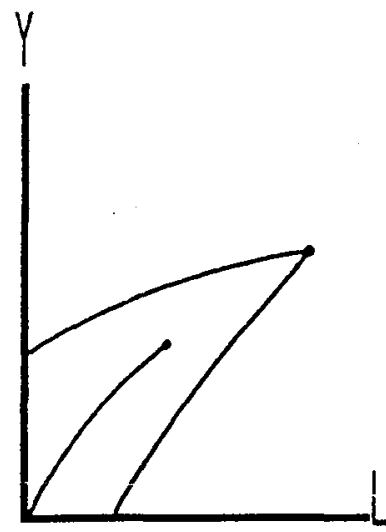

(c)

Figure 22 Types of equilibria in the inventoryless model. 
Now the entire parameter space is two-dimensional; $x=(w, m)$. Therefore, we need only one graph to summarize the location of the different types of equilibria in the state space for dynamic studies. Informally, this graph can be derived from collapsing the UE region out of the diagram in ( $w, m)$ space derived above for the general model (see figure 21a).

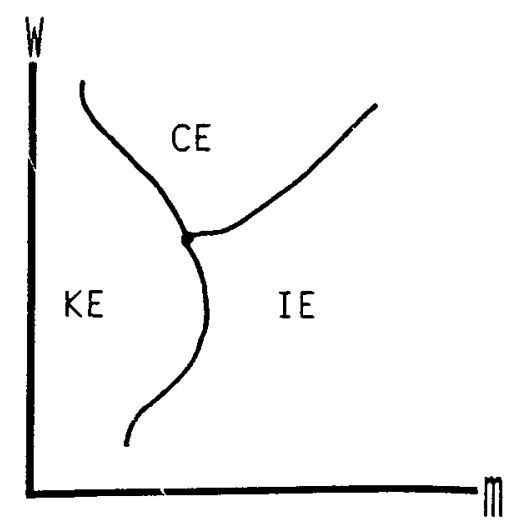

Figure 23 Equilibrium locations in the parameter space for the inventoryless model.

V. Summary

This completes our specification of fixprice models. We have seen that if prices fail to clear markets, many outcomes are possible, depending on values of exogenous parameters. Static models are the first step to disequilibrium models of recessions, and more generally of business cycles. This paper gives the disequilibrium explanation for existence of these observed outcomes. In Working Paper 8505, we extend these models to dynamic settings. In such models, Keynesian outcomes can be stationary states, explaining the persistence of output fluctuations. 


\section{References}

Arrow, Kenneth J., and F.H. Hahn. General Competitive Analysis. San Francisco: Holden Day Inc., 1971.

Barro, Robert J., and Herschel I. Grossman. "A General Disequilibrium Model of Income and Employment," The American Economic Review, vol. 61, no.1 (March 1971), pp. 82-93.

Benassy, Jean-Pascal. "On Quantity Signals and the Foundation of Effective Demand Theory," Scandanavian Journal of Economics, vol. 79, no. 2, (1977), pp. 147-68.

"The Disequilibrium Approach to Monopolistic Price Setting and General Monopolistic Equilibirum," Review of Economic Studies 43:1 (February 1976), pp. 69-81.

"Neo-Keynesian Disequilibrium Theory in a Monetary Economy," Review of Economic Studies, 42:4 (October 1975), pp.503-23.

Bohm, Volker. "Disequilibrium Dynamics in a Simple Macroeconomic Mode1," Journal of Economic Theory, vol. 17, pp. 179-99.

Clower, Robert $W$. "The Keynesian Counterrevolution: A Theoretical Appraisal," in F.H. Hahn and F.P.R. Brechling, eds., The Theory of Interest Rates, London: Macmillan, 1965.

Debreu, Gerard. "Economies with a Finite Set of Equilibria," Econometrica, vol. 38, no. 3 (May 1970) pp. 387-92.

The Theory of Value. Cowles Foundation Monograph \#17, New Haven: Yale University Press, 1959.

Dehez, P., and J. Gabszewicz. "On the Convergence of Sequences of Disequilibria," CORE Discussion Paper No. 7701, 1977.

Drazen, Allen. "Recent Developments in Macroeconomic Disequilibrium Theory," Econometrica, vol. 48, no. 2 (March 1980), pp. 283-306.

Dreze, Jacques H. "Existence of an Exchange Equilibrium under Price Rigidities," International Economic Review, vol. 16, no. 2 (June 1975), pp. $301-20$.

Eckstein, Otto, and G. Fromm. "The Price Equation, "American Economic Review, vol. 58, no. 5 (December 1968), pp. 59-83. 
Fisher, Franklin M. Disequilibrium Foundations of Equilibrium Theory. Econometric Society Monograph in Pure Theory \#6, New York: Cambridge University Press, 1984.

Godley, W.A.H., and W.D. Nordhaus. "Pricing and the Trade Cycle," Economic Journal, vol. 82, no. 327 (September 1972), pp. 853-82.

Grandmont, Jean-Michel. "Temporary General Equilibrium Theory," in Kenneth J. Arrow and Michael D. Intriligator, eds. Handbook of Mathematical Economics: Volume II. Amsterdam: North-Holland Publishing Company, 1982 , pp. 879-922.

. "The Logic of the Fix-Price Method," Scandanavian Journal of Economics, vol. 79, no. 2(1977), pp. 169-86.

, A.P. Kirman, and W. Neuefeind. "A New Approach to the Uniqueness of Equilibrium," Review of Economic Studies, vol. 41, no. 126 (April 1974), pp. 289-91.

Hahn, Frank H. "On Non-Walrasian Equilibria," Review of Economic Studies, 45:1 (February 1978), pp. 1-17.

"Exercises in Conjectural Equilibria, Scandanavian Journal of Economics, vol. 79, no. 2 (1977), pp. 210-26.

Hansen, Bent. A Survey of General Equilibirum Systems. New York: McGraw-Hi11, 1970 .

Hicks, Sir John. The Crisis in Keynesian Economics. New York, NY: Basic Books, Publishers Inc., 1974.

Honkapohja, Seppo. "On the Dynamics of Disequilibria in a Macro Model with Flexible Wages and Prices," in Masanao and A. Marzollo, eds., New Trends in Dynamic System Theory and Economics. New York, NY: Academic Press, 1979.

, and Takatoshi Ito. "Non-trivial Equilibrium in an Economy with Stochastic Rationing, "NBER Working Paper \#322, February 1979.

Keynes, John Maynard. The General Theory of Employment, Interest, and Money, London: MacMi

Laroque, Guy. "On the Local Uniqueness of the Fixed Price Equilibria," Review of Economic Studies, 48:1 (February 1981), pp. 113-29.

Leijonhufvud, Axel. On Keynesian Economics and the Economics of Keynes. New York, NY: Oxford University Press, 1968. 
Malinvaud, Edmond. Profitability and Unemployment. Cambridge, England: Cambridge University Press, 1980.

. The Theory of Unemployment Reconsidered. Blackwel1: Oxford University Press, 1977.

Muellbauer, John, and Richard Portes. "Macroeconomic Models with Quantity Rationing. "Economic Journal, vol. 88 (December 1978), pp. 788-821.

Okun, Arthur. "Inflation: Its Mechanics and Welfare Cost," Brookings Papers on Economic Activity 1975:2, pp. 351-90.

Patinkin, Don. Money, Interest, and Prices, New York, NY: Harper \& Row Publishers, 1965.

Samuelson, Paul Anthony. Foundations of Economic Analysis. New York, NY: Atheneum, 1979.

Silvestre, Joaquim, "Fixprice Analysis in Productive Economies," Journal of Economic Theory, vol. 30, no. 2 (August 1983), pp. 401-9.

"Fixprice Analysis in Exchange Economies," Journal of Economic Theory, vol. 26, no. 1 (February 1982), pp. 28-58.

Sneessens, Henri R. "Theory and Estimation of Macroeconomic Rationing Models," in M. Beckmann and H.P. Kunzi, eds., Lecture Notes in Economics and Mathematical Systems, vol. 191. Berlin: Springer-Verlag, 1981.

Tobin, James. Asset Accumulation and Economic Activity. Chicago: The University of Chicago Press, 1980.

Varian, Hal R. "Non-Walrasian Equilibria," Econometrica, vol. 45, no. 3 (Apri1 1977), pp. 573-90. 